\title{
Fortified breakfast cereal consumed daily for 12 wk leads to a significant improvement in micronutrient intake and micronutrient status in adolescent girls: a randomised controlled trial
}

\author{
Hilary J. Powers ${ }^{1 *}$, Mark Stephens ${ }^{1}$, Jean Russell ${ }^{2}$ and Marilyn H. Hill ${ }^{1}$
}

\begin{abstract}
Background: Poor micronutrient status is reported among adolescents across Europe and USA. This may be related to the well-documented decline in the regular consumption of breakfast by this group. The regular consumption of a breakfast cereal offers a possible means to improve micronutrient status; fortified cereal is likely to have enhanced benefit. A study was conducted to determine the efficacy of the regular consumption of a fortified cereal with milk, compared with unfortified cereal, consumed either as a breakfast or a supper, in improving micronutrient intake and micronutrient status of adolescent girls.
\end{abstract}

Methods: A randomised, double-blind, placebo-controlled intervention trial was conducted in girls recruited at ages 16-19 years, from schools and colleges in Sheffield, UK. Girls were randomised to receive $50 \mathrm{~g}$ fortified or unfortified cereal, with $150 \mathrm{ml}$ semi-skimmed milk, daily, for 12 weeks, as a breakfast or as a supper. Dietary intake was estimated using a 4-d food diary and blood collected for the assessment of nutritional status. Within-group changes were tested using a paired sample t test; two-way ANOVA was used to analyse effects of the intervention, with cereal type and time of consumption as factors, correcting for baseline values. The analysis was conducted on 71 girls who completed the study.

Results: Consumption of unfortified cereal elicited an increase in the intake of vitamins $B_{1}, B_{2}$ and $B_{6}$; consumption of fortified cereal elicited increases in vitamins $B_{1}, B_{2}, B_{6}, B_{12}$, folate and iron $(P<0.001)$ and of vitamin $D(P=0.007)$, all increases were significantly greater than for unfortified cereal. Consumption of the fortified cereal also led to a significant improvement in biomarkers of status for vitamins $B_{2}, B_{12}$, folate and of iron, compared with girls receiving the unfortified cereal, and maintained vitamin D status, in contrast with the girls receiving the unfortified cereal $(P<0.001)$.

Conclusions: The daily consumption of cereal with milk for 12 weeks by adolescent girls, increased intakes of micronutrients. The consumption of fortified cereal elicited greater increases than for unfortified cereal and improved biomarkers of micronutrient status. The findings justify strategies to encourage the consumption of fortified cereal with milk by adolescents, either as a breakfast or a supper.

Trial registration: Registered with Current Controlled Trials (Registration: ISRCTN55141306)

Keywords: Fortified cereal, Breakfast, Vitamin and mineral status, Micronutrients, Adolescents

* Correspondence: h.j.powers@sheffield.ac.uk

${ }^{1}$ Human Nutrition Unit, University of Sheffield, Sheffield, UK

Full list of author information is available at the end of the article 


\section{Background}

Data from the National Diet and Nutrition Surveys (NDNS) of the UK indicate low intakes of some micronutrients and poor nutritional status among adolescent girls, with concern over vitamin $\mathrm{B}_{2}$ (riboflavin), vitamin D, calcium and iron [1]. Dietary data from the National Health and Nutrition Examination Surveys (NHANES) in the USA also show that adolescents are at higher risk of nutritional deficiencies than other age groups in the population [2]. Some of these deficiencies may be of particular functional importance to adolescent females given that they are of childbearing age and that low micronutrient intakes in this group influence risk of anaemia, peak bone mass attainment and adverse effects in the offspring [3-7].

Breakfast consumption by children and adolescents has declined over recent decades in many developed countries [8-12]. Milk consumption by children and adolescents in developed countries is also falling, and this is thought to associate with the declining trend in breakfast cereal consumption $[1,13,14]$ Studies of association have identified a number of correlates of breakfast consumption in adolescents. Cross sectional studies have reported associations between regular consumption of breakfast and parameters of a healthy lifestyle and some measures of nutritional status $[15,16]$. Breakfastskipping is associated with increased likelihood of being a smoker, of being a consumer of alcohol, of engaging in little exercise and having a higher BMI [17]. On the other hand, some studies report that breakfast consumers have higher energy consumption than nonconsumers, and may be associated with an increase in the contribution of fat to total energy intake [18]. A cross-sectional study in Belgium showed that the type of breakfast consumed was associated with the overall dietary intake profile in adolescents [19]. There is some evidence that a breakfast of cereal may have particular value [20] although it is not clear whether associations reported between breakfast cereal consumption and various biomarkers of health are attributable to the consumption of breakfast cereals per se, as part of a daily diet, or the consumption of the cereal as part of a breakfast meal.

There is a definite gender bias in the decline of breakfast consumption, with girls significantly more likely to miss breakfast than boys $[17,20]$. There is also an agerelated decline in breakfast consumption, with older adolescents more likely to miss breakfast [21]. Reasons often cited are lack of time, loss of appetite in the morning, tiredness or personal choice [22]. Dieting and a desire to lose weight is another reason given for not eating breakfast [23, 24].

The lack of randomised controlled trials to examine hypotheses linking the regular consumption of breakfast cereals to particular health benefits is an obstacle to making specific dietary recommendations.

The study reports that the daily consumption of a fortified cereal with milk, either at breakfast time or supper time for twelve weeks, elicits an increase in micronutrient intake and improvement in biomarkers of micronutrient status in adolescent girls who regularly skip breakfast, that is significantly greater than that observed by the consumption of unfortified cereal with milk. In contrast with girls receiving the unfortified cereal, all girls consuming the fortified cereal achieved the Recommended Nutrient Intake (RNI) for vitamins $B_{2}, B_{6}, B_{12}$ and folate, although they did not all achieve the RNI for iron, and no girl achieved the current RDA (USA) for vitamin $\mathrm{D}$. The RNI reflects the intake considered to satisfy the requirements of $97.5 \%$ of the age and genderspecific population group.

\section{Study aim}

This study aimed to investigate the efficacy of the regular consumption of fortified cereal with milk, compared with unfortified cereal, either as a breakfast or a supper, in improving micronutrient intake and micronutrient status of adolescent girls who self-report regularly skipping breakfast.

\section{Hypotheses}

We hypothesised that the regular consumption of a fortified breakfast cereal with milk by adolescent girls who often skip breakfast will elicit an increased intake of some micronutrients and improvement in biomarkers of micronutrient status, compared with unfortified cereal. We also hypothesised that the consumption of breakfast cereal at supper-time will elicit the same improvements in nutritional status as when consumed at breakfast time.

\section{Methods \\ Study design}

The study was a randomised, placebo-controlled, doubleblind intervention trial conducted over a twelve-week period (Sheffield University Breakfast Study - SUBS).

\section{Recruitment}

\section{Ethics approval and consent}

Ethics approval was obtained from Sheffield University Research Ethics Committee (Ref. SMBRER 223). Informed written consent was taken at the screening visit for the whole study.

\section{Recruitment}

Adolescent girls aged 16-19 years were selected for this study because the National Diet and Nutrition Survey (NDNS) of the UK and data from other developed 
countries, show that poor nutritional status is prevalent in this group [1, 2]. Girls were recruited from schools, colleges and Universities within the Sheffield area. An Amazon voucher for $£ 30$ was offered on completion of the study.

\section{Eligibility}

Inclusion criteria

Participants had to be female, aged between 16 and 19 years at the time of recruitment, who self-reported missing breakfast at least 4 times a week. They had to have no diagnosed illness and have low measures of riboflavin status and haemoglobin, as these have previously been found to track well with self-reported breakfast skipping [3].

\section{Exclusion criteria}

Potential participants were not recruited if they used multivitamin or iron supplements, had donated blood in the previous 6 months, were pregnant or breast feeding or had an allergy to wheat, barley or milk.

\section{Screening}

Recruitment to the study used a website which invited girls who self-reported skipping breakfast at least four times a week. Girls who responded were then screened for low riboflavin status and poor iron status. A screening visit was held to confirm eligibility, to answer any queries and concerns, to take consent, to collect additional information (such as date of birth, address and medication usage) and to take a small finger prick sample $(\sim 100 \mu \mathrm{l})$ for the measurement of riboflavin and iron status. Consent was taken for both the screening and the main intervention study. Blood samples were analysed for riboflavin status using the erythrocyte glutathione reductase activation coefficient assay (EGRAC) and hemoglobin concentration measured on-site using a portable Hemocue device (Hemocue Hb 201+ DM System, Hemocure, AB, Sweden). EGRAC is the most commonly used biomarker for riboflavin status. Samples with a low riboflavin status have a higher EGRAC value. An EGRAC value of $>1.30$ is conventionally used to indicate poor riboflavin status [3]. In this study, girls with an EGRAC value $>1.40$ and a hemoglobin of $<137 \mathrm{~g} / \mathrm{L}$ were eligible for the main study.

\section{Sample size}

Sample size was based on improvement in riboflavin status following the consumption of a fortified cereal with milk. Findings from the RIBOFEM study [3] showed that a supplement of $2 \mathrm{mg}$ riboflavin per day for 8 weeks in young women elicits a fall in EGRAC of 0.25 . This cereal study would provide $1.7 \mathrm{mg}$ riboflavin per day for 12 weeks to adolescent girls, in addition to habitual dietary intake. It was anticipated that the intervention would achieve a similar fall in EGRAC and that the baseline SD would be $\sim 0.20$ on the basis of the RIBOFEM study. Standardised effect size was estimated to be 1.56 . It was estimated that we would need 17 girls for each of 4 groups (cereal type and time of intervention) allowing for a possible $25 \%$ dropout in this age and gender group. We therefore aimed to recruit 70 girls to the study.

\section{Cereal}

The cereal, supplied by Kellogg Marketing and Sales Company, was a wheat, rice and barley-based flake similar to their Special K cereal supplied in the UK. Unfortified and fortified cereal was provided and the identity of each was blinded to the researchers and participants. Participants were provided with an equal amount of plain and fruit cereal to add variety and improve compliance. Table 1 shows the estimated macronutrient and micronutrient intakes achieved from the consumption of unfortified and fortified cereal with milk.

\section{Intervention and randomisation}

Girls who were eligible for the main intervention study were invited to attend three clinics over a period of 12 weeks at the Clinical Research Facility at the Hallamshire Hospital, Sheffield. Prior to attending the first intervention clinic visit, girls were sent a study guide with instructions for the study, a timetable for the scheduled visits and a 4-d food diary to complete. They were also provided with a colour portion guide

Table 1 Nutrient and energy supplied by the cereal and milk intervention

\begin{tabular}{lll}
\hline Nutrient & $\begin{array}{l}50 \mathrm{~g} \text { fortified cereal } \\
+150 \mathrm{ml} \text { milk }\end{array}$ & $\begin{array}{l}50 \mathrm{~g} \text { unfortified cereal } \\
+150 \mathrm{ml} \text { milk }\end{array}$ \\
\hline Energy (kcal) & 257 & 257 \\
Fat $(\mathrm{g})$ & 3.1 & 3.1 \\
Carbohydrate $(\mathrm{g})$ & 47.8 & 47.8 \\
Sugars $(\mathrm{g})$ & 15.9 & 15.9 \\
Vitamin D $(\mu \mathrm{g})$ & 4.15 & 0.2 \\
Vitamin C $(\mathrm{mg})$ & 51.5 & 1.5 \\
Vitamin $\mathrm{B}_{1}(\mathrm{mg})$ & 1.21 & 0.36 \\
Vitamin $\mathrm{B}_{2}(\mathrm{mg})$ & 1.71 & 0.61 \\
Niacin $(\mathrm{mg})$ & 17.8 & 1.4 \\
Vitamin $\mathrm{B}_{6}(\mathrm{mg})$ & 1.74 & 0.64 \\
Folic Acid $(\mu \mathrm{g})$ & 176 & 18 \\
Vitamin $\mathrm{B}_{12}(\mu \mathrm{g})$ & 1.45 & 0.60 \\
Iron $(\mathrm{mg})$ & 6.5 & 0.75 \\
Calcium $(\mathrm{mg})$ & 215 & 215 \\
\hline
\end{tabular}

From Windiets and Kellogg's published data

(http://www.kelloggs.co.uk/en GB/special-k-html)

Values are averages of the berry and original varieties 
booklet to facilitate portion size estimation. Girls were instructed to record dietary information for four consecutive days, including one weekend day.

Volunteers were randomised in blocks of twelve to receive a daily intake of either fortified or unfortified cereal (50 g) with semi-skimmed milk $(150 \mathrm{ml})$ for 12 weeks, to be consumed at breakfast time or at supper-time. Volunteers were provided with a graduated measuring jug that indicated the cereal and milk portion sizes. 'Breakfast' refers to the first meal of the day, after an overnight fast; 'supper' refers to the last food consumed in the day, generally after an earlier complete meal, usually considered as 'dinner'. Previous experience had indicated that daily consumption of this amount of cereal and milk would be acceptable to volunteers.

\section{Visit 1 (week 0)}

The purpose of this visit was to collect baseline data and blood samples, to review completed pre-intervention food diaries, and to give the volunteers the first six weeks cereal supply. The girls were weighed using a digital Salter scale and their height measured using a stadiometer for adults. A fasted venous blood sample $(6-7 \mathrm{ml})$ was collected. Girls were given instructions as to how and when to consume the cereal and milk and given tick sheets to record if and when they ate the cereal, for compliance assessment. At this visit, girls were given their next food diary to complete one week prior to visit 2 .

\section{Visit 2 (week 6)}

At this visit the second diet diary was reviewed and girls were given the remainder of the cereal for the study. Any cereal that was not eaten was collected and weighed and used as a second measure of compliance.

\section{Visit 3 (week 12)}

At this final visit girls provided another venous blood sample and their height and weight were recorded. Any remaining cereal was collected for estimating compliance.

\section{Blood collection}

Blood was collected by venepunture from fasted volunteers in the morning, for plasma biochemical analysis $(4.5 \mathrm{ml}$, EDTA vacutainer) and for routine hematology measurements ( $2 \mathrm{ml}$, EDTA vacutainer). Blood cells and plasma were separated by centrifugation, and the plasma divided into aliquots and stored at $-80{ }^{\circ} \mathrm{C}$ for biochemical analysis. A hemolysate was prepared from the red blood cell pellet and stored at $-80{ }^{\circ} \mathrm{C}$ for EGRAC measurements [3], to determine vitamin $\mathrm{B}_{2}$ status.

\section{Hematological measurements}

Hemoglobin, hematocrit, MCV and red cell number were measured in the hematology laboratory at the Royal Hallamshire Hospital, Sheffield. If the laboratory report indicated 'suggestive of iron deficiency' at baseline, on the basis of low hemoglobin, ferritin and MCV, subjects were informed and withdrawn from the study.

\section{Biochemical techniques}

The choice of biochemical measurements of micronutrient status was informed primarily by those nutrients for which there is evidence of poor intake and/or status in adolescent girls, and which might therefore be expected to be influenced by the regular consumption of a fortified cereal.

\section{Plasma ferritin for estimating iron stores}

Plasma ferritin was measured by ELISA using a commercially available kit (Spectro Ferritin Kit, ATi Atlas Ltd. Chichester, UK). An external quality control was used to monitor accuracy and precision (Randox). The intra-batch coefficient of variation $(\mathrm{CV})$ for QC1 $(14 \mathrm{ng} / \mathrm{mL})$ was $3.4 \%$ and for $\mathrm{QC} 2(80 \mathrm{ng} / \mathrm{mL})$ was $13.1 \%$. The interbatch $\mathrm{CV}$ for QC1 $(14 \mathrm{ng} / \mathrm{mL})$ was $1.6 \%$ and for QC2 (80 ng/mL) was $8.5 \%$. If the CV for sample replicates was greater than $10 \%$, these measurements were repeated.

Plasma holotranscobalamin (holoTC) for vitamin $B_{12}$ status Vitamin $B_{12}$ status was assessed as its active form, holotranscobalamin, in plasma, using an ELISA kit (ActiveB12 supplied by AXIS-SHIELD). The intra-batch CV for QC1 $(25 \mathrm{nmol} / \mathrm{L})$ was $3.1 \%$ and for QC2 $(60 \mathrm{nmol} / \mathrm{L})$ was $12.5 \%$. The inter-batch $\mathrm{CV}$ for QC1 $(25 \mathrm{nmol} / \mathrm{L})$ was $5.1 \%$ and for QC2 $(60 \mathrm{nmol} / \mathrm{L})$ was $3.5 \%$. If the CV for sample replicates was greater than $15 \%$, these measurements were repeated.

Plasma 5-methyltetrahydrofolate(5-MeTHF) for folate status Plasma 5-MeTHF was measured by reverse-phase HPLC with fluorescence detection using a method described by Loehrer [25]. 5-MeTHF was detected fluorometrically at excitation and emission wavelengths of $295 \mathrm{~nm}$ and $365 \mathrm{~nm}$, respectively. The intra-batch $\mathrm{CV}$ for the QC was $2.2 \%$ and the inter-batch $\mathrm{CV}$ was $4.6 \%$.

\section{Plasma 25-hydroxyvitamin D (25(OH)D for vitamin D status}

The Bone Metabolism Group in the Faculty of Medicine, Dentistry and Health at Sheffield University measured plasma total 25-hydroxyvitamin D using an electrochemiluminescence binding method on a COBAS e 411auto analyser (Roche Diagnostics, Germany). The inter assay CV for total vitamin D was $5.7 \%$. 


\section{Erythrocyte glutathione reductase activation coefficient (EGRAC) for vitamin $B_{2}$ status}

The activity of erythrocyte glutathione reductase (EC 1.6.4.2) was measured in haemolysates using the method described by Glatzle et al. [26], and modified by Hill et al. [27] for use on the Cobas Autoanalyser, (Roche Diagnostica). Results were expressed as an activation coefficient, EGRAC. The intra batch $\mathrm{CV}$ was $2.9 \%$ and the inter batch $\mathrm{CV}$ was $1.25 \%$.

\section{Dietary assessment}

In order to monitor any changes in diet during the intervention and to assess dietary habits in this population of girls, dietary information was collected prior to and during the study. Four-day estimated food intake diaries were used, modified from those developed by the Institute of Food Research (IFR), Norwich, UK. The volunteers were also given food portion booklets developed by IFR and (based on the Ministry of Agriculture, Fisheries and Food (MAFF) food atlas [28] to assist in the recording of portion sizes. Data from the food diaries were analyzed for micronutrient and macronutrient contents with Windiets Research software (version 2010; Robert Gordon University, Aberdeen, United Kingdom).

\section{Compliance}

Two measures were used to assess compliance with the intervention. The completed tick sheets were used to assess self-reported compliance, which is a measure of occasions on which the cereal was consumed. The weight of cereal returned at the end of the study was used to estimate cereal consumed as a percentage of that requested.

\section{Statistical analysis}

Data sets did not deviate significantly from the normal distribution (Kolmogorov-Smirnov test). Data are therefore presented as mean \pm SD. Analysis of the effects of the intervention on nutrient and energy intake and biomarkers of nutritional and haematological status, was by two-factor ANOVA ( $F$ test), with cereal type and time of consumption as factors, correcting for baseline values. When ANOVA indicated a significant difference according to cereal type or time of consumption, a KruskalWallis multiple-comparison $\mathrm{z}$ value test was carried out, to identify where the differences lay. Within-group differences between baseline and follow-up were analysed using a paired sample $t$ test. Comparison of percentage of girls falling outside normal thresholds for nutritional status was determined using Chi square test. Statistical analysis was performed using SPSS v.20 (IBM, Hampshire, UK). Significance was taken as $P<0.05$.

\section{Results}

Subject recruitment, retention and compliance Recruitment

Figure 1 details the flow of participants through the study. 198 girls were screened for moderate riboflavin and iron status, of whom 101 were eligible for the intervention trial. Of these, 78 girls agreed to take part in the main study. Five girls failed to complete the main study (one was withdrawn because of iron deficiency anaemia diagnosed by the Royal Hallamshire Hospital Haematology Department). Data are shown and analyses were conducted on data from 71 girls for whom there was a complete dataset. Of these, 37 girls had been randomised to receive unfortified cereal, 34 to receive fortified cereal. The main study was run alongside the screening and took place over 11 months between July 2012 and May 2013.

\section{Compliance}

On the basis of self-reported occasions on which cereal was consumed, compliance (mean $\pm \mathrm{SD}$ ) to the intervention was $91 \pm 7.1 \%$ ( $n=63$ responders). On the basis of the weight of cereal returned, compliance to the cereal consumption was $102 \pm 10.3 \%(n=71)$; indicating that some girls consumed more than the weight of cereal they were asked to. Using this metric, compliance was lower in the girls receiving the unfortified cereal $(98 \pm 10.2 \%)$ than the girls receiving the fortified cereal $(105 \pm 9.2 \%), P=0.004$. Girls who consumed their cereal as a 'breakfast' had a

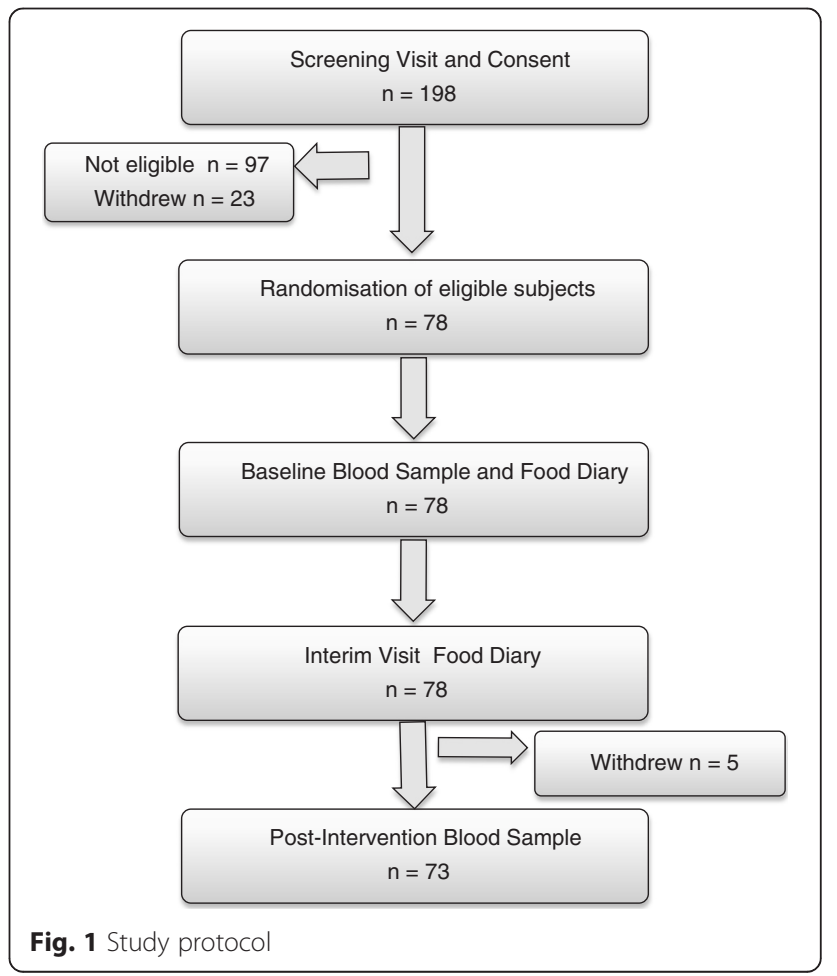


median time of consumption of $0930 \mathrm{~h}$, the median time of consumption as a 'supper' was 2130 h. Time of consumption (as breakfast or supper), did not influence compliance, by either metric.

\section{Subject characteristics}

Table 2 shows subject ages, weight, height and BMI, according to cereal type and time of consumption. The age distribution of girls completing the study was as follows: 5 at $16 y, 7$ at $17 y, 22$ at $18 y, 36$ at $19 y$ and 1 who turned $20 y$ between screening and starting the intervention. Analysis of variance revealed no significant differences in these variables between the randomisation groups.

\section{Baseline biochemistry}

Markers of micronutrient and hematological status

Table 2 also shows values for biochemical and hematological variables at baseline, according to cereal type and time of consumption. Analysis of variance revealed no differences in any of these variables between randomisation groups at baseline. Mean $( \pm$ SD) EGRAC was higher (1.63 \pm 0.21 vs $1.52 \pm 0.20)$ and mean plasma ferritin ( $20 \pm 13.4$ vs $28 \pm 22.9 \mu \mathrm{g} / \mathrm{L})$ and hemoglobin concentrations were lower $(128 \pm 8.1 \mathrm{vs} 131 \pm 8.78 \mathrm{~g} / \mathrm{L})$ than the means $( \pm \mathrm{SD})$ for girls of this age group in the UK, reported in NDNS [1]. Mean $( \pm \mathrm{SD})$ plasma $25(\mathrm{OH}) \mathrm{D}$ concentration $(40.8 \pm 25.9)$ was comparable with the NDNS mean $( \pm \mathrm{SD})$ of $42.5 \pm$ $21.5 \mathrm{nmol} / \mathrm{L}$.

\section{Adequacy of micronutrient status}

All girls fell above the conventional threshold of $>1.30$ for EGRAC, indicating low riboflavin status. $46 \%$ the girls had evidence of low vitamin $\mathrm{B}_{12}$ status (plasma holoTC $<37 \mathrm{pmol} / \mathrm{L}$ and iron status (plasma ferritin < $15 \mathrm{ng} / \mathrm{mL}$ ) whilst $32 \%$ of the group had low vitamin D status (plasma 25(OH)D $<25 \mathrm{nmol} / \mathrm{L}$ ).

\section{Dietary intakes}

Intakes of macronutrients and energy at baseline are shown in Table 3. There were no differences in any variable between cereal groups or according to time of consumption but there was an interaction between these factors for non-milk extrinsic sugars (NMES) sugars (g), sugars (\% energy), total carbohydrate (g) and carbohydrate (\% energy).

Intakes of micronutrients are shown in Table 4. There were no differences in intakes between cereal groups or according to time of consumption but there was an interaction between these factors for folate intake. At least half of the girls had intakes of vitamin $B_{2}$ and $B_{6}$, folate, iron and calcium lower than both the UK Recommended Nutrient Intakes (RNIs) and the Dietary Reference Intakes (DRIs) for USA. There are currently no DRV's for vitamin D for people between the ages of 4 and $65 y$ in the UK [29], and therefore comparison was made with the recommendation from the Institute of Medicine (IOM) [30]. Intakes of vitamin D were lower

Table 2 Baseline characteristics of girls who completed the intervention

\begin{tabular}{|c|c|c|c|c|c|c|c|c|c|c|c|}
\hline & \multicolumn{4}{|c|}{ Unfortified cereal } & \multicolumn{4}{|c|}{ Fortified cereal } & \multicolumn{3}{|l|}{$P$ value ${ }^{\mathrm{e}}$} \\
\hline & \multicolumn{2}{|c|}{ Morning $(n=21)$} & \multicolumn{2}{|c|}{ Evening $(n=16)$} & \multicolumn{2}{|c|}{ Morning $(n=18)$} & \multicolumn{2}{|c|}{ Evening $(n=16)$} & \multirow[t]{2}{*}{ Cereal type } & \multirow[t]{2}{*}{ Timing } & \multirow[t]{2}{*}{ Interaction } \\
\hline & Mean & SD & Mean & $\mathrm{SD}$ & Mean & SD & Mean & SD & & & \\
\hline Height (cm) & 165 & 6.25 & 165 & 4.06 & 164 & 6.44 & 164 & 6.95 & 0.383 & 0.853 & 0.639 \\
\hline Weight (kg) & 59.6 & 5.94 & 59.5 & 7.50 & 62.5 & 11.35 & 60.2 & 10.87 & 0.397 & 0.575 & 0.627 \\
\hline BMI $\left(\mathrm{kg} / \mathrm{m}^{2}\right)$ & 21.8 & 2.08 & 22.0 & 3.00 & 23.3 & 3.34 & 22.0 & 2.73 & 0.178 & 0.578 & 0.370 \\
\hline Age (y) & 19.0 & 1.06 & 19.1 & 0.70 & 18.6 & 1.09 & 19.1 & 0.74 & 0.494 & 0.225 & 0.304 \\
\hline \multicolumn{12}{|c|}{ Biochemical and hematological status values } \\
\hline EGRAC ${ }^{a}$ & 1.71 & 0.27 & 1.63 & 0.22 & 1.58 & 0.15 & 1.59 & 0.11 & 0.071 & 0.519 & 0.361 \\
\hline Plasma holoTC ${ }^{b}$ (pmol/L) & 40.6 & 16.90 & 40.08 & 15.95 & 34.6 & 12.68 & 34.1 & 14.12 & 0.143 & 0.806 & 0.839 \\
\hline Plasma 5MeTHF ${ }^{c}$ (nmol/L) & 14.1 & 7.74 & 17.1 & 8.45 & 17.0 & 9.50 & 17.2 & 6.18 & 0.364 & 0.328 & 0.557 \\
\hline Plasma 25(OH)D $\mathrm{D}^{\mathrm{d}}(\mathrm{nmol} / \mathrm{L})$ & 37.1 & 20.72 & 42.6 & 25.63 & 33.8 & 21.87 & 50.3 & 33.34 & 0.632 & 0.062 & 0.316 \\
\hline Plasma ferritin (ng/ml) & 23.9 & 13.57 & 18.8 & 15.41 & 19.7 & 11.03 & 17.9 & 13.69 & 0.519 & 0.360 & 0.511 \\
\hline Hemoglobin (g/L) & 127 & 7.9 & 128 & 8.3 & 129 & 6.9 & 129 & 9.5 & 0.235 & 0.641 & 0.882 \\
\hline Hematocrit & 0.38 & 0.03 & 0.38 & 0.03 & 0.38 & 0.02 & 0.39 & 0.03 & 0.967 & 0.153 & 0.377 \\
\hline Mean cell volume (fl) & 85.8 & 3.67 & 84.1 & 5.01 & 83.9 & 3.41 & 84.4 & 4.49 & 0.348 & 0.451 & 0.348 \\
\hline
\end{tabular}

erythrocyte glutathione reductase activation coefficient

bolotranscobalamin

'5-methyltetrahydrofolate

${ }^{d} 25$-hydroxyvitamin D

edifferences between groups according to cereal type, timing of consumption, and interactions 
Table 3 Daily intakes of macronutrients and energy at baseline ${ }^{a}$

\begin{tabular}{|c|c|c|c|c|c|c|c|c|c|c|c|}
\hline & \multicolumn{4}{|c|}{ Unfortified cereal } & \multicolumn{4}{|c|}{ Fortified cereal } & \multicolumn{3}{|l|}{$P$ value $^{d}$} \\
\hline & \multicolumn{2}{|c|}{ Morning $(n=21)$} & \multicolumn{2}{|c|}{ Evening $(n=16)$} & \multicolumn{2}{|c|}{ Morning $(n=18)$} & \multicolumn{2}{|c|}{ Evening $(n=16)$} & \multirow[t]{2}{*}{ Cereal type } & \multirow[t]{2}{*}{ Timing } & \multirow[t]{2}{*}{ Interaction } \\
\hline & Mean & SD & Mean & SD & Mean & SD & Mean & SD & & & \\
\hline Energy (kJ) & 6756 & 2203 & 7318 & 2196 & 7712 & 2144 & 6426 & 2108 & 0.921 & 0.521 & 0.092 \\
\hline Fat (g) & 61 & 26.2 & 65 & 25.6 & 71 & 25.0 & 61 & 24.6 & 0.644 & 0.696 & 0.253 \\
\hline Fat (\% energy) & 33.6 & 6.33 & 32.5 & 6.32 & 32.9 & 6.16 & 34.1 & 6.04 & 0.793 & 0.975 & 0.453 \\
\hline Protein (g) & 59 & 19.8 & 57 & 10.0 & 63 & 19.2 & 58 & 18.9 & 0.567 & 0.471 & 0.809 \\
\hline Carbohydrate (g) & 196 & 67.3 & 229 & 67.3 & 238 & 65.3 & 187 & 64.3 & 0.963 & 0.582 & 0.011 \\
\hline Carbohydrate (\% energy) & 46.3 & 6.24 & 50.8 & 6.00 & 49.9 & 71.28 & 46.8 & 6.85 & 0.870 & 0.693 & 0.010 \\
\hline Sugars (g) & 72 & 37.3 & 96 & 36.7 & 101 & 36.3 & 70 & 36.0 & 0.814 & 0.749 & 0.003 \\
\hline Sugars (\% energy) & 16.7 & 6.02 & 20.1 & 5.96 & 21.9 & 5.79 & 17.0 & 5.69 & 0.394 & 0.662 & 0.006 \\
\hline Starch (g) & 113 & 42.9 & 122 & 4.2 & 126 & 41.7 & 104 & 41.0 & 0.806 & 0.452 & 0.114 \\
\hline $\operatorname{NMES}^{\mathrm{b}}(\mathrm{g})$ & 50 & 33.5 & 75 & 33.0 & 75 & 32.6 & 48 & 27.6 & 0.947 & 0.945 & 0.002 \\
\hline $\operatorname{NSP}^{c}(\mathrm{~g})$ & 8.9 & 3.72 & 9.9 & 3.71 & 11.1 & 3.68 & 9.7 & 3.64 & 0.251 & 0.813 & 0.184 \\
\hline Alcohol (g) & 11.9 & 12.22 & 8.6 & 12.0 & 6.33 & 11.9 & 6.0 & 11.69 & 0.190 & 0.574 & 0.557 \\
\hline Alcohol (\% energy) & 5.1 & 5.20 & 2.5 & 5.47 & 2.89 & 5.26 & 3.14 & 5.65 & 0.403 & 0.592 & 0.231 \\
\hline
\end{tabular}

a energy and nutrient intakes determined using 4-day estimated diet diaries, aided by the use of portion size booklets

bnon-milk extrinsic sugars

cnon-starch polysaccharides

d differences according to cereal type, time of consumption and interaction

than the IOM Estimated Average Requirement (EAR) of $10 \mu \mathrm{g}$ per day in all of the girls.

\section{Effects of the intervention}

\section{Effects of the intervention on nutritional status and} haematological biomarkers

The effects of the intervention on biochemical and hematological variables are shown in Table 5. Data are presented for values before and after intervention, according to cereal type. Two-way ANOVA revealed no effect of the time of consumption of the cereal on any variable and therefore the table shows results for morning and evening consumption combined, for the fortified and unfortified cereal.

Paired sample $t$ test revealed a significant fall (improvement) in EGRAC, and a significant increase in plasma holotranscobalamin, plasma 5-MeTHF and plasma ferritin after the intervention in the girls receiving the fortified cereal. Plasma 25(OH)D concentration fell in the girls receiving the unfortified cereal, but was maintained at the preintervention value in the group receiving the fortified cereal. Mean cell volume fell in both groups. When the

Table 4 Daily intakes of micronutrients at baseline $e^{a}$

\begin{tabular}{|c|c|c|c|c|c|c|c|c|c|c|c|}
\hline & \multicolumn{4}{|c|}{ Unfortified cereal } & \multicolumn{4}{|c|}{ Fortified cereal } & \multicolumn{3}{|l|}{$P$ value $^{\mathrm{b}}$} \\
\hline & \multicolumn{2}{|c|}{ Morning $(n=21)$} & \multicolumn{2}{|c|}{ Evening $(n=16)$} & \multicolumn{2}{|c|}{ Morning $(n=18)$} & \multicolumn{2}{|c|}{ Evening $(n=16)$} & \multirow[t]{2}{*}{ Cereal type } & \multirow[t]{2}{*}{ Timing } & \multirow[t]{2}{*}{ Interaction } \\
\hline & Mean & SD & Mean & SD & Mean & SD & Mean & SD & & & \\
\hline Vitamin $B_{1}(\mathrm{mg})$ & 1.08 & 0.46 & 1.09 & 0.44 & 1.33 & 0.46 & 0.98 & 0.44 & 0.490 & 0.109 & 0.095 \\
\hline Vitamin $B_{2}(\mathrm{mg})$ & 0.97 & 0.41 & 1.06 & 0.40 & 1.28 & 0.42 & 0.98 & 0.4 & 0.200 & 0.366 & 0.068 \\
\hline Niacin (mg) & 24.2 & 9.71 & 25.0 & 9.68 & 28.3 & 9.58 & 26.2 & 9.40 & 0.228 & 0.830 & 0.576 \\
\hline Vitamin $B_{6}(\mathrm{mg})$ & 1.17 & 0.51 & 1.27 & 0.48 & 1.50 & 0.46 & 1.21 & 0.48 & 0.321 & 0.334 & 0.065 \\
\hline Vitamin $B_{12}(\mu \mathrm{g})$ & 3.32 & 1.66 & 2.76 & 1.64 & 2.83 & 1.64 & 2.70 & 1.60 & 0.541 & 0.438 & 0.539 \\
\hline Folate $(\mu \mathrm{g})$ & 138 & 61 & 161 & 60 & 189 & 60 & 148 & 59 & 0.176 & 0.606 & 0.039 \\
\hline Vitamin D $(\mu \mathrm{g})$ & 1.55 & 1.33 & 1.51 & 1.32 & 1.93 & 1.30 & 1.53 & 1.28 & 0.501 & 0.525 & 0.620 \\
\hline Calcium (mg) & 676 & 283 & 677 & 282 & 771 & 280 & 631 & 274 & 0.637 & 0.360 & 0.358 \\
\hline Sodium (mg) & 2373 & 805 & 2480 & 804 & 2449 & 794 & 2167 & 776 & 0.609 & 0.725 & 0.365 \\
\hline Iron (mg) & 8.06 & 2.57 & 8.51 & 2.60 & 9.54 & 2.56 & 7.45 & 2.52 & 0.699 & 0.207 & 0.050 \\
\hline
\end{tabular}

${ }^{a}$ nutrient intakes determined using 4-day estimated diet diaries, aided by the use of portion size booklets

${ }^{b}$ differences according to cereal type, time of consumption, and interaction 
Table 5 Nutritional status and hematological biomarkers following intervention

\begin{tabular}{|c|c|c|c|c|c|}
\hline \multirow[t]{3}{*}{ Analyte } & \multicolumn{2}{|c|}{ Unfortified cereal $(n=37)$} & \multicolumn{2}{|c|}{ Fortified cereal $(n=34)$} & \multirow[t]{3}{*}{$P$ value } \\
\hline & Pre-intervention & Post-intervention & Pre-intervention & Post-intervention & \\
\hline & Mean (SD) & Mean (SD) & Mean (SD) & Mean (SD) & \\
\hline EGRAC $^{\mathrm{b}}$ & $1.68(0.25)$ & $1.65(0.18)$ & $1.58(0.13)$ & $1.38(0.15)^{*}$ & $<0.001$ \\
\hline Plasma holoTC ${ }^{\mathrm{C}}$ (pmol/L) & $40.7(16.27)$ & $39.4(7.44)$ & $35.3(12.94)$ & $42.8(13.66)^{* *}$ & $<0.001$ \\
\hline Plasma $5 \mathrm{MeTHF}{ }^{\mathrm{d}}(\mathrm{nmol} / \mathrm{L})$ & $15.4(8.09)$ & $14.1(6.90)$ & $17.3(7.96)$ & $32.9(16.16)^{* *}$ & $<0.001$ \\
\hline Plasma $25(\mathrm{OH}) \mathrm{D}^{\mathrm{e}}(\mathrm{nmol} / \mathrm{L})$ & $39.4(22.77)$ & $30.6(18.74)^{*}$ & $42.5(29.21)$ & $43.7(28.22)$ & $<0.001$ \\
\hline Plasma ferritin (ng/ml) & $21.7(14.42)$ & $18.4(11.63)$ & $19.3(12.38)$ & $22.1(16.73)^{* *}$ & $<0.001$ \\
\hline Hemoglobin (g/L) & $128(8.03)$ & $128(6.63)$ & $130(7.96)$ & $130(7.68)$ & 0.876 \\
\hline Hematocrit & $0.38(0.03)$ & $0.38(0.02)$ & $0.38(0.02)$ & $0.38(0.02)$ & 0.687 \\
\hline Mean cell volume (fl) & $85.0(4.31)$ & $84.1(4.33)^{*}$ & $84.0(3.84)$ & $83.2(3.82)^{*}$ & 0.876 \\
\hline
\end{tabular}

*significantly lower than value pre-intervention (paired $t$ test; $P<0.05$ )

${ }^{*}$ significantly higher than value pre-intervention (paired $t$ test; $P<0.05$ )

${ }^{a}$ significance of difference between cereal groups after intervention, corrected for baseline (ANOVA)

berythrocyte glutathione reductase activation coefficient

cholotranscobalamin

${ }^{\mathrm{d}} 5$-methyltetrahydrofolate

e 25 -hydroxyvitamin D

effect of the intervention was compared between cereal types, girls eating the fortified cereal showed a significant improvement in biomarkers of vitamin $B_{2}$, vitamin $B_{12}$, folate, and vitamin D status and of plasma ferritin, compared with girls receiving the unfortified cereal.

\section{Effects of intervention on the percentage of girls with} nutrient biomarkers below the lower limits for normality

Table 6 shows the percentage of girls who would be considered as 'deficient' in specific micronutrients, according to the stated threshold for each biomarker. Data are shown as percentages before and after the intervention, according to cereal type. Three thresholds are used for EGRAC; the conventional threshold is 1.30 but it has been suggested that a higher threshold should be used to reflect a functional deficiency [3], therefore 1.40 and 1.60 are used too. For girls receiving the fortified cereal, there was a significant decrease in the percentage with biomarker values below the lower limit of normality (or above the EGRAC thresholds) when compared with girls receiving unfortified cereal, for vitamin $B_{2}$, vitamin $B_{12}$ and folate.

\section{Effects of intervention on nutrient intakes Macronutrients and energy}

There were no significant differences in post-intervention values between consumers of unfortified and fortified cereal. Within-group analysis revealed a significant decrease from the pre-intervention value for fat and carbohydrate as a percentage of energy, and an increase in starch (Table 7).

Table 6 Effects of cereal intervention on percentage of girls falling below ${ }^{a}$ biochemical thresholds for normality

\begin{tabular}{|c|c|c|c|c|c|}
\hline \multirow[t]{2}{*}{ Analyte } & \multirow[t]{2}{*}{ Threshold } & \multicolumn{2}{|l|}{ Unfortified cereal } & \multicolumn{2}{|l|}{ Fortified cereal } \\
\hline & & Pre-intervention & Post-intervention & Pre-intervention & Post-intervention \\
\hline EGRAC $^{\mathrm{b}}$ & $>1.3$ & 100 & 100 & 100 & $63^{*}$ \\
\hline EGRAC & $>1.4$ & 95 & 97 & 94 & $42^{*}$ \\
\hline EGRAC & $>1.6$ & 60 & 57 & 47 & $8^{*}$ \\
\hline Plasma HoloTC ${ }^{c}$ & $<37 \mathrm{pmol} / \mathrm{L}$ & 46 & 51 & 53 & $36^{*}$ \\
\hline Plasma 5MeTHF ${ }^{d}$ & $<14 \mathrm{nmol} / \mathrm{L}$ & 11 & 8 & 14 & $0^{*}$ \\
\hline Plasma $25(\mathrm{OH}) \mathrm{D}^{\mathrm{e}}$ & $<25 \mathrm{nmol} / \mathrm{L}$ & 32 & 46 & 31 & 31 \\
\hline Plasma ferritin & $<15 \mathrm{ng} / \mathrm{ml}$ & 46 & 49 & 50 & 44 \\
\hline Hemoglobin & $<120 \mathrm{~g} / \mathrm{L}$ & 24 & 14 & 11 & 15 \\
\hline Mean cell volume (fl) & $<84 \mathrm{fl}$ & 27 & 49 & 46 & 53 \\
\hline
\end{tabular}

*significantly different from girls in the unfortified group (Chi Squared test; $P<0.05$ )

a above threshold values for EGRAC

berythrocyte glutathione reductase activation coefficient

cplasma holotranscobalamin

dplasma 5-methyl tetrahydrofolate

eplasma 25-hydroxyvitamin D 
Table 7 Intakes of macronutrients and energy following intervention ${ }^{a}$

\begin{tabular}{|c|c|c|c|c|c|}
\hline \multirow{3}{*}{ Nutrient } & \multicolumn{2}{|c|}{ Unfortified cereal $(n=37)$} & \multicolumn{2}{|c|}{ Fortified cereal $(n=34)$} & \multirow{3}{*}{$P$-value ${ }^{d}$} \\
\hline & Pre-intervention & Post-intervention & Pre-intervention & Post-intervention & \\
\hline & Mean (SD) & Mean (SD) & Mean (SD) & Mean (SD) & \\
\hline Energy (kcals) & $1665(526)$ & $1732(377)$ & $1695(534)$ & $1743(329)$ & 0.952 \\
\hline Fat (g) & $63(23)$ & $62(18)$ & $67(29)$ & $58(19)$ & 0.269 \\
\hline Fat (\% energy) & $33(6)$ & $31(5)^{*}$ & $33(7)$ & $29(6)^{*}$ & 0.078 \\
\hline Protein (g) & $59(19)$ & $70(16)^{* *}$ & $61(20)$ & $67(17)$ & 0.357 \\
\hline Carbohydrate (g) & $210(66)$ & $230(53)$ & $214(74)$ & $242(45)^{* *}$ & 0.351 \\
\hline Carbohydrate (\% energy) & $48(6)$ & $51(6)^{* *}$ & $48(7)$ & $53(6)^{* *}$ & 0.063 \\
\hline Sugars (g) & $82(41)$ & $81(32)$ & $87(37)$ & $92(32)$ & 0.173 \\
\hline Sugars (\% energy) & $18(6)$ & $18(5)$ & $20(7)$ & $20(6)$ & 0.086 \\
\hline $\operatorname{NMES}^{\mathrm{b}}(\mathrm{g})$ & $61(37)$ & $55(27)$ & $63(34)$ & $63(32)$ & 0.273 \\
\hline Starch (g) & $116(32)$ & $142(32)^{* *}$ & $115(53)$ & $137(30)^{* *}$ & 0.441 \\
\hline $\operatorname{NSP}^{c}(g)$ & $9(3)$ & $10(3)$ & $10(4)$ & $10(3)$ & 0.734 \\
\hline Alcohol (g) & $11(15)$ & $4(7)^{*}$ & $6(8)$ & $5(8)$ & 0.304 \\
\hline Alcohol (\% energy) & $4(6)$ & $2(3)^{*}$ & $3(4)$ & $2(3)^{*}$ & 0.359 \\
\hline
\end{tabular}

*significantly lower than value pre-intervention (paired $t$ test; $P<0.05$ )

**significantly higher than value pre-intervention (paired $t$ test; $P<0.05$ )

a energy and nutrient intakes determined using 4-day estimated diet diaries, aided by the use of portion size booklets

${ }^{b}$ non-milk extrinsic sugars

'Non-starch polysaccharides

${ }^{d}$ significance of differences between cereal groups, corrected for baseline

An increase in protein and carbohydrate was observed which reached statistical significance for the consumers of unfortified and fortified cereal, respectively. Alcohol intake as a percentage of energy showed a decrease from baseline in response to cereal intervention; there was no effect of cereal type.

Vitamins, minerals and trace elements

Within-group analysis showed that consuming the unfortified cereal improved intake of vitamins $B_{1}, B_{2}$ and $\mathrm{B}_{6}$, and consuming the fortified cereal improved intakes of all fortificants - vitamins $B_{1}, B_{2}$, niacin, $B_{6}$, $\mathrm{B}_{12}, \mathrm{C}, \mathrm{D}$, folate and iron (Table 8). The intake of these nutrients was significantly greater than for girls receiving unfortified cereal; there was no effect of time of consumption. There was no difference between groups in the effect of the interventions on calcium intakes, although within-group analysis showed an increase in the girls receiving the milk with unfortified cereal.

Table 8 Daily intake of micronutrients following intervention ${ }^{a}$

\begin{tabular}{|c|c|c|c|c|c|}
\hline \multirow[t]{3}{*}{ Nutrient } & \multicolumn{2}{|c|}{ Unfortified cereal $(n=37)$} & \multicolumn{2}{|c|}{ Fortified cereal $(n=34)$} & \multirow[t]{3}{*}{$P$ value } \\
\hline & Pre-intervention & Post-intervention & Pre-intervention & Post-intervention & \\
\hline & Mean (SD) & Mean (SD) & Mean (SD) & Mean (SD) & \\
\hline Vitamin $B_{1}(\mathrm{mg})$ & $1.1(0.40)$ & $1.3(0.35)^{* *}$ & $1.2(0.50)$ & $2.2(0.36)^{* *}$ & $<0.001$ \\
\hline Vitamin $B_{2}(\mathrm{mg})$ & $1.0(0.41)$ & $1.4(0.35)^{* *}$ & $1.2(0.43)$ & $2.7(0.50)^{* *}$ & $<0.001$ \\
\hline Niacin (mg) & $25(8.1)$ & $27(9.0)$ & $27(11.1)$ & $41(10.3)^{* *}$ & $<0.001$ \\
\hline Vitamin $B_{6}(\mathrm{mg})$ & $1.2(0.45)$ & $1.8(0.40)^{* *}$ & $1.3(0.53)$ & $3.0(0.64)^{* *}$ & $<0.001$ \\
\hline Vitamin $B_{12}(\mu \mathrm{g})$ & $3.1(1.81)$ & $2.8(1.09)$ & $2.8(1.44)$ & $4.1(1.78)^{* *}$ & $<0.001$ \\
\hline Folate $(\mu \mathrm{g})$ & $148(55)$ & $151(61)$ & $171(69)$ & $314(54)^{* *}$ & $<0.001$ \\
\hline Vitamin D $(\mu \mathrm{g})$ & $1.5(1.35)$ & $1.6(0.91)$ & $1.8(1.28)$ & $5.5(1.32)^{* *}$ & 0.007 \\
\hline Calcium (mg) & $677(282)$ & $822(248)^{* *}$ & $713(282)$ & $775(177)$ & $<0.001$ \\
\hline Sodium (mg) & $2419(7367)$ & $2528(631)$ & $2335(863)$ & $2576(637)$ & 0.628 \\
\hline Iron (mg) & $8.3(2.47)$ & $7.7(2.37)$ & $8.9(2.86)$ & $13.1(2.31)^{* *}$ & $<0.001$ \\
\hline
\end{tabular}

** significantly higher than pre-intervention (paired $t$ test; $P<0.05$ )

${ }^{a}$ nutrient intakes determined using 4-day estimated diet diaries, aided by the use of portion size booklets

${ }^{b}$ significance of difference between cereal groups corrected for baseline values (ANOVA) 


\section{Effect of intervention on percentage of girls with intakes below recommended intakes}

Intakes of micronutrients following the intervention were compared with RNIs for the UK and DRIs for USA. After intervention with fortified cereal all girls had intakes of vitamins $B_{2}$ and $B_{6}$ that exceeded both sets of recommendations. Intakes of folate and vitamin $\mathrm{B}_{12}$ also achieved UK recommendations but fell short of DRIs; no girl achieved the recommended DRI for folate (Table 9). A high percentage of girls in this group still had iron intakes below both sets of recommendations, but none of the girls had an iron intake less than the Lower Reference Nutrient Intake (LRNI) for the UK, which represents an intake that satisfies the requirement of only $2.5 \%$ of the population. In contrast, after intervention with unfortified cereal, micronutrient intakes less than both sets of recommendations persisted across all micronutrients with the exception of vitamin $\mathrm{B}_{6}$. Although calcium was not a fortificant, the cereal and milk intervention increased calcium intakes but overall, intakes fell short of RNIs and DRIs in at least $50 \%$ of girls, after the intervention. Although vitamin D intakes increased significantly in the fortified group, and were higher in the fortified group post-intervention, than the unfortified group, intakes still fell short of the EAR of $10 \mu \mathrm{g}$ proposed by IOM [30].

Two-way ANOVA, correcting for baseline showed no effect of cereal type or time of consumption on weight or BMI. However, analysis of weight and BMI for all evening consumers, regardless of whether the cereal was fortified or not, showed a small but significant increase in weight (mean $\pm \mathrm{SD}, 0.93 \pm 1.96 \mathrm{~kg}$ ) over the intervention period $(P=0.012)$, which was not seen in girls consuming the cereal in the morning (mean \pm SD, $0.27 \pm$ $1.64 \mathrm{~kg})$.

\section{Discussion}

The consumption of fortified cereal with milk elicited very clear benefits in terms of increased intakes of some vitamins and iron, and significant improvements in biomarkers of nutritional status. The beneficial effects were seen whether the cereal with milk was consumed in the morning or the evening. The consumption of unfortified cereal with milk also showed some benefit but this was restricted to a few nutrients and was modest compared with the fortified cereal. This observation is important because previous statements about the health benefits of breakfast consumption in any age group have relied almost entirely on observational studies, which could only show associations. Girls taking part in the study had micronutrient intake and status profiles comparable with those reported in the NDNS, so the findings can be considered relevant to their gender and age group.

After 12 weeks of consuming a fortified cereal with milk each day all girls achieved intakes of at least RNI for all micronutrients except for iron and calcium. Intakes were still lower than the DRI for folate and vitamin $\mathrm{D}$ for all the girls. Several observational studies have shown that regular breakfast consumption among young people is associated with higher intakes of some micronutrients, including folate, vitamin $\mathrm{D}$, calcium, iron and zinc $[31,32]$, although details of the type of breakfast consumed are often lacking. Concern has been expressed about a low intake of vitamin D in some sections of the UK population, and there is evidence for poor vitamin D status in some groups [1]; low intakes of this vitamin in adolescents are reported for several other European countries [33]. Vitamin D intake increased significantly in the girls receiving the fortified cereal and this was sufficient to maintain vitamin D status over the period of the intervention, in contrast with the girls receiving the unfortified cereal, in whom vitamin D status fell during the study. This is important because there are few good dietary sources of vitamin D [34] and people living in the Northern hemisphere generally show a decline in plasma concentrations of $25(\mathrm{OH}) \mathrm{D}$ during the winter months [35]. The study was conducted during winter and summer months, when potential for dermal

Table 9 Effect of intervention on percentage of girls with micronutrient intakes below recommendations

\begin{tabular}{|c|c|c|c|c|c|c|c|c|}
\hline \multirow[t]{2}{*}{ Diet } & \multicolumn{2}{|c|}{$\begin{array}{l}\text { \% below RNI } \\
\text { Unfortified cereal }\end{array}$} & \multicolumn{2}{|c|}{$\begin{array}{l}\text { \% below RNI } \\
\text { Fortified cereal }\end{array}$} & \multicolumn{2}{|c|}{$\begin{array}{l}\text { \% below DRI/RDA }{ }^{a} \\
\text { Unfortified cereal }\end{array}$} & \multicolumn{2}{|c|}{$\begin{array}{l}\text { \% below DRI/RDA } \\
\text { Fortified cereal }\end{array}$} \\
\hline & Pre & Post & Pre & Post & Pre & Post & Pre & Post \\
\hline Vitamin B-2 & 62.2 & 18.9 & 50 & 0 & 62.2 & 18.9 & 50 & 0 \\
\hline Vitamin B-6 & 54.1 & 9.5 & 50 & 0 & 54.1 & 9.5 & 50 & 0 \\
\hline Vitamin B-12 & 18.9 & 13.5 & 25 & 0 & 35.1 & 35.1 & 44.1 & 14.7 \\
\hline Folate & 78.4 & 86.5 & 72.2 & 0 & 100 & 100 & 100 & 100 \\
\hline Iron & 97.3 & 100 & 97.2 & 82.9 & 97.3 & 100 & 97.2 & 82.9 \\
\hline Calcium & 70.3 & 48.6 & 66.7 & 60 & 97.3 & 94.6 & 97.1 & 97.1 \\
\hline Vitamin $D^{a}$ & $\mathrm{~N} / \mathrm{A}$ & $\mathrm{N} / \mathrm{A}$ & $\mathrm{N} / \mathrm{A}$ & N/A & 100 & 100 & 100 & 100 \\
\hline
\end{tabular}

pre, post refer to values before and after intervention, RNI recommended nutrient intake (UK), DRI Dietary Reference Intake (USA) ${ }^{\mathrm{R} D A}$ (Recommended Dietary Allowance) from the Institute of Medicine Report (31) 
synthesis of vitamin D would have been different but the block randomisation method would have minimised differences in any seasonal effect on vitamin D synthesis between the groups. The regular consumption of a cereal fortified with vitamin D could make a useful contribution to dietary vitamin $\mathrm{D}$ and evidently has the potential to mitigate the seasonal deterioration in vitamin D status.

This simple intervention had a clear beneficial effect in terms of nutrient intake in this vulnerable group. This was true whether the cereal was consumed in the morning or the evening, offering potentially important flexibility in terms of a public health message.

There is very limited evidence that the consumption of a fortified breakfast cereal leads to an improvement in micronutrient status, due to the lack of randomised controlled trials. Tucker and colleagues [36] conducted a study in adults aged 50-85y, focussed on effects of fortified cereal on plasma homocysteine concentration. They reported improvements in vitamin $\mathrm{B}_{6}, \mathrm{~B}_{12}$ and folate status as well as a decrease in homocysteine concentration. Whilst this is of interest, adolescents are more likely to skip breakfast [16, 21, 22], making it particularly important to demonstrate beneficial effects of breakfast cereal consumption in this group. In our trial, compared with the girls receiving unfortified cereal, consumption of the fortified cereal led to significant improvements in biomarkers of vitamin $B_{2}, B_{12}$, vitamin $D$ and folate status as well as plasma ferritin, a biomarker of hepatic iron stores. Despite the increase in iron stores elicited by the fortified cereal intervention compared with the unfortified cereal, no increase in hemoglobin was observed and there was no difference in hemoglobin concentration between the two groups following the intervention. An increase in iron stores following the intervention would suggest that iron delivery to the site of hemoglobin synthesis was adequate, and that hemoglobin synthesis was not compromised at the outset. Additional available iron in the diet would then be stored as hepatic iron. There were no differences in mean hemoglobin at baseline between the cereal groups but fewer girls receiving fortified cereal had low hemoglobin $(<12 \mathrm{~g} / \mathrm{L})$, which may have influenced ferritin responses in this group. An intervention study carried out in New Zealand among women with low iron stores, demonstrated a beneficial effect on iron status of consuming an iron-fortified breakfast cereal together with kiwi fruit, which has a high vitamin $\mathrm{C}$ content, compared with cereal consumed with banana [37]. Although a direct comparison of this study with the present study is difficult to make, given differences in age of the women, and iron status at the outset, the results suggest that the vitamin $C$ content of fortified cereal may be inadequate to maximise absorption of cereal iron.
There is very little information available regarding the nutritional status of adolescent breakfast consumers compared with non-consumers. The majority of studies have paid more attention to obesity and measures of metabolic health than biomarkers of nutritional status. A recent study of younger children in Cyprus reported no difference in plasma ferritin concentration between consumers and non-consumers [38].

Despite the unequivocal improvement in micronutrient status in the girls receiving fortified cereal, and the decrease in the percentage of girls falling below the biomarker thresholds for normality, the improvement was insufficient to bring all girls into the normal range for conventional biomarkers of status except for folate. The normalisation of folate status is of particular relevance to this study population, given the importance of good folate status to healthy pregnancy [39].

Girls consuming cereal in the evening showed a small but significant increase in weight, which was not seen in the girls consuming cereal in the morning. The two-way ANOVA, correcting for baseline values, did not reveal any difference between groups, suggesting that undue emphasis should not be placed on the within-group finding. It is possible that cereal consumed in the evening is less likely to displace other foods, but this was not reflected in a significant increase in energy intake in the evening consumers. Others have explored effects of breakfast habits on energy intake and there have been several reports that breakfast skipping causes a compensatory increase in energy intake later in the day [40]. There may be differences in physical activity following cereal consumed as a breakfast or as a supper. Betts et al. [41] recently reported that daily breakfast consumption was associated with an increase in energy expenditure during the morning of the breakfast. The mean weight gain reported in our study was small and it will be important to know whether this was maintained or lost if evening cereal consumption was sustained over a longer period.

The cereal and milk intervention led to a modest but significant decrease in the proportion of dietary fat as a percentage of total energy intake and an increase in the proportion of energy derived from carbohydrate. This, together with the lack of increase in energy intake suggests that the cereal may have displaced fat-rich foods from the diet of these girls. This is compatible with the findings of Deshmuk-Taskar et al. [42], who reported a lower intake of fat and a higher intake of carbohydrate in children and adolescents who consumed ready to eat breakfast cereal (RTEC) compared with non-consumers. There is also a small literature suggesting that breakfast consumption may influence snacking behaviour such as to reduce energy intake from snacks and reduce snacking frequency [43]. Utter et al. [44] reported that 
skipping breakfast is associated with a greater frequency of snacking in New Zealand teenagers. It is possible that the cereal and milk intervention had the effect of reducing the consumption of fat-rich snacks; this is the subject of further investigation. Before the intervention, analysis indicated a significant interaction between various measures of carbohydrate intake; this seemed to be a result of between-group differences in mean values (not-significant) for these variables at baseline. The interaction was not evident post-intervention and we do not ascribe particular significance to the observation.

In conclusion, the daily consumption of a micronutrientfortified breakfast cereal for 12 weeks, in the morning or the evening, by adolescent girls in the UK, improved status indices for vitamins $B_{2}, B_{12}$, folate, and iron. For each of these micronutrients this effect was significantly greater than benefits of consuming a non-fortified cereal. Vitamin D status was maintained in girls consuming fortified cereal in contrast with a decline seen in girls consuming unfortified cereal. Consuming cereal in the evening, whether fortified or non-fortified, elicited a modest weight gain but this was not associated with an increase in energy intake. To our knowledge this is the only randomised controlled trial of cereal intervention in adolescents reporting on dietary intake and micronutrient status. These findings are relevant across age and gender groups but have particular importance during the transition from childhood to adolescence, which is generally associated with less healthy dietary choices. The findings contribute to our understanding of the value of developing strategies to encourage the regular consumption of breakfast cereal in adolescents.

\section{Limitations of the study}

Dietary intake was estimated using 4-day diet diaries, supported by food portion booklets; the use of weighed records would have produced more reliable data but the additional burden would probably have reduced ease of recruitment to the study and jeopardised compliance. In retrospect it would have been useful to have determined energy expenditure before and during the intervention, given the reported influence of breakfast consumption on morning energy expenditure. However, this would have entailed a significant demand on participants and may have reduced compliance. It may also have been useful to have explored the prevalence of mis-reporting of dietary data, although this is a complex subject to examine and the randomisation design should have minimised the impact on the main findings.

\section{Strengths of the study}

To our knowledge this is the only randomised placebo controlled intervention trial that has attempted to determine the effects of consuming breakfast cereal and milk on micronutrient intake and status in adolescents. The separation of the intervention into a morning and an evening consumption added value in that this allowed us to demonstrate the potential benefits of consuming cereal with milk in an evening as an alternative to morning consumption.

\section{Acknowledgements \\ The Kelloggs Company of Great Britain provided the cereal for the study and financial support for the research. They had no role whatsoever in the design and execution of the study, in the writing of the manuscript, the data analysis or the interpretation of the results. The salary of HJP and JR was provided by the University of Sheffield, that of MHH by Kelloggs Company of Great Britain. MS was a Master's student with no income.}

\section{Authors' contributions}

The study was conceived and designed by HJP, MHH and JR; MHH and MS carried out the day to day work; JR carried out the statistical analysis; HJP drafted the manuscript, all authors contributed to the final version. All authors read and approved the final manuscript.

\section{Competing interests}

The authors declare that they have no competing interests.

\section{Author details}

${ }^{1}$ Human Nutrition Unit, University of Sheffield, Sheffield, UK. ${ }^{2}$ Corporate Information and Computing Services, University of Sheffield, Sheffield, UK.

Received: 1 December 2015 Accepted: 29 June 2016

Published online: 14 July 2016

\section{References}

1. Public Health England and Food Standards Agency. National Diet and Nutrition Survey:Results from Years 1 to 4 (combined) of the Rolling programme for 2008/2009 to 2011/2012. https://www.gov.uk/government/ uploads/system/uploads/attachment_data/file/310995/NDNS_Y1_to_4_UK_ report.pdf Published May 2014 PHE publications gateway number:2014051. Accessed 24 Oct 2016

2. Second National Report on Biochemical Indicators of Diet and Nutrition in the US PopulationCDC2012 (www.cdc.gov/nutritionreport/pdf/ ExecSummary_Web_032612.pdf). 24 Oct 2016.

3. Powers HJ, Hill MH, Mushtaq S, Dainty JR, Majsak-Newman G, Williams EA. Correcting a marginal riboflavin deficiency improves hematological status in young women in the United Kingdom (RIBOFEM). Am J Clin Nutr. 2011;93(6):1274-84.

4. Aranda N, Ribot B, Garcia E, Viteri FE, Arija V. Pre-pregnancy iron reserves, iron supplementation during pregnancy and birth weight. Early Hum Dev. 2011:87(12):791-7.

5. Chesnut 3rd CH. Is osteoporosis a pediatric disease? Peak bone mass attainment in the adolescent female. Public Health Rep. 1989;104 Suppl:50-4.

6. Faulkner RA, Bailey DA. Osteoporosis: a pediatric concern? Med Sport Sci. 2007:51:1-12.

7. Young BE, McNanley TJ, Cooper EM, Mclntyre AW, Witter F, Harris ZL, et al. Maternal vitamin $D$ and calcium interact to affect fetal growth in utero in pregnant adolescents. Am J Clin Nutr. 2012;95(5):1103-12.

8. Dror DK, Allen LH. Dairy product intake in children and adolescents in developed countries: trends, nutritional contribution, and a review of association with health outcomes. Nutr Rev. 2013;72(2):68-81.

9. Pearson N, Biddle SJ, Gorely T. Family correlates of breakfast consumption among children and adolescents. A systematic review. Appetite. 2009;52(1):1-7.

10. Pearson N, MacFarlane A, Crawford D, Biddle SJH. Family circumstances and adolescent behaviours. Appetite. 2009;52(3):668-74.

11. Rampersaud GC, Pereira MA, Girard BL, Adams J, Metzl JD. Breakfast habits, nutritional status, body weight, and academic performance in children and adolescents. J Am Diet Assoc. 2005;105(5):743-60.

12. Siega-Riz AM, Popkin BM, Carson T. Trends in breakfast consumption in the United States from 1965-1991. Am J Clin Nutr. 1998;67:S748-56.

13. Bowman SA. Beverage choices of young females: changes and impact on nutrient intakes. J Am Diet Assoc. 2002;102:1234-9.

14. Lioret S, Dubuisson C, Dufour A, Touvier M, Calamassi-Tran G, Maire B, et al. Trends in food intake in French children from 1999 to 2007: results from the 
INCA (etude Individuelle Nationale des Consommation Alimentaires) dietary surveys. Brit J Nutr. 2010;103(4):585-601.

15. Sandercock GR, Voss C, Dye L. Associations between habitual school-day breakfast consumption, body mass index, physical activity and cardiorespiratory fitness in English schoolchildren. Eur J Clin Nutr. 2010; 64(10):1086-92.

16. Sjoberg A, Hallberg L, Hoglund D, Hulthen L. Meal pattern, food choice, nutrient intake and lifestyle factors in The Goteborg Adolescence Study. Eur J Clin Nutr. 2003;57(12):1569-78.

17. Keski-Rahkonen A, Kaprio J, Rissanen A, Virkunnen M, Rose RJ. Breakfast skipping and health-compromising behaviours in adolescents and adults. Eur J Clin Nutr. 2003;57:842-53.

18. Belderson P, Harvey I, Kimbell R, O'Neill J, Russell J, Barker ME. Does breakfast-club attendance affect children's nutrient intake? A study of dietary intake at three schools. Br J Nutr. 2003:90:1003-6.

19. Matthys C, De Henauw S, Bellemans M, De Maeyer M, De Backer G. Breakfast habits affect overall nutrient profiles in adolescents. Public Health Nutr. 2007;10(4):413-21.

20. Barr SI, DiFranceso L, Fulgoni III VL. Consumption of breakfast and the type of breakfast consumed are positively associated with nutrient intakes and adequacy of Canadian adults. J Nutr. 2013:143:86-92.

21. Gibson S, Gunn P. What's for breakfast? Nutritional implications of breakfast habits: insights from the NDNS dietary records. Nutr Bull. 2011;36:78-86.

22. Raaijmakers LG, Bessems KM, Kremers SP, van Assema P. Breakfast consumption among children and adolescents in the Netherlands. Eur J Public Health. 2010;20:318-24.

23. Reddan J, Wahlstrom K, Reicks M. Children's perceived benefits and barriers in relation to eating breakfast in schools with or without Universal School Breakfast. J Nutr Educ Behav. 2002;34(1):47-52.

24. Shaw ME. Adolescent breakfast-skipping: an Australian study. Adolescence. 1998;33(132):851-61

25. Loehrer FM, Angst CP, Haefeli WE, Jordan PP, Ritz R, Fowler B. Low wholeblood S-adenosylmethionine and correlation between 5methyltetrahydrofolate and homocysteine in coronary artery disease. Arterioscler Thromb Vasc Biol. 1996;16(6):727-33.

26. Glatzle D, Korner WF, Christeller S, Wiss O. Method for the detection of a biochemical riboflavin deficiency. Stimulation of NADPH2-dependent glutathione reductase from human erythrocytes by FAD in vitro. Investigations on the vitamin B-2 status in healthly people and geriatric patients. Int Z Vitaminforsch. 1970:40(2):166-83.

27. Hill MH, Bradley A, Mushtaq S, Williams EA, Powers HJ. Effect of methodological variation on assessment of riboflavin status using the erythrocyte glutathione reductase coefficient assay. Br J Nutr. 2009;102(2):273-8.

28. Nelson M, Atkinson M, Meyer J. Food portion sizes: a photographic atlas: food standards agency. 2002.

29. Department of Health. Dietary reference values for food energy and nutrients for the United Kingdom. Report on health and social subjects; 41. London: Her Majesty's Stationary Office; 1991.

30. IOM (Institute of Medicine). Dietary reference intakes for calcium and vitamin D. Washington DC: The National Academies Press, 2011. .

31. Barton BA, Eldridge AL, Thompson D, Affenito SG, Striegel-Moore RH, Franko DL, et al. The relationship of breakfast and cereal consumption to nutrient intake and body mass index: the National Heart, Lung, and Blood Institute Growth and Health Study. J Am Diet Assoc. 2005;105(9):1383-9.

32. Michels N, de Henauw S, Briedenassel C, Censi L, Cuenca-Garci M, Gonzales-Gross M, et al. European adolescent ready-to-eat-cereal (RTEC) consumers have a healthier dietary intake and body composition compared with non-RTEC consumers. Eur J Nutr. 2015;54:653-64.

33. Mensink GBM, Fletcher R, Gurinovic M, Huybrechts I, Lafay L, SerraMajem $L$, et al. Mapping low intakes of micronutrients across Europe. $\mathrm{Br}$ J Nutr. 2013;110(4):755-73.

34. Black $\sqcup$, Walton J, Flynn A, Kiely M. Adequacy of vitamin D intakes in children and teenagers from the base diet, fortified foods and supplements. Public Health Nutr. 2014;17:721-31.

35. Logan VF, Gray AR, Peddie MC, Harper MJ, Houghton LA. Long-term vitamin D3 supplementation is more effective than vitamin D2 at maintaining 25-hydroxy vitamin D status over the winter months. $\mathrm{Br}$ J Nutr. 2013;109(6):1082-8.

36. Tucker KL, Olson B, Bakun P, Dallal GE, Selhub J, Rosenberg $\|_{\text {. }}$. Breakfast cereal fortified with folic acid, vitamin B-6 and vitamin B-12 increases vitamin concentrations and reduces homocysteine concentrations: a randomised trial. Am J Clin Nutr. 2004;79(5):805-11.

37. Beck K, Conlon CA, Kruger R, Coad J, Stonehouse W. Consumption of an iron-fortified breakfast cereal together with kiwifruit improved iron status in women with low iron stores compared with consuming with a banana. $\mathrm{Br} J$ Nutr. 2011;105(1):101-9.

38. Lazarou C, Matalas A-L. Breakfast intake is associated with nutritional status, Mediterranean diet adherence, serum iron and fasting glucose: the CYFamilies study. Public Health Nutr. 2015;18(7):1308-16.

39. Obeid R, Koletzko B, Pietrzik K. Critical evaluation of lowering the recommended intake of folate. Clin Nutr. 2014:33(2):252-9.

40. Astbury NM, Taylor MA, MacDonald IA. Breakfast consumption affects appetite, energy intake and the metabolic and endocrine responses to foods consumed later in the day in male habitual breakfast eaters. J Nutr. 2011;141(7):1381-9.

41. Betts JA, Richardson JD, Chowdhury EA, Holman GD, Tsintzas K, Thompson D. The causal role of breakfast in energy balance and health: a randomised controlled trial in lean adults. Am J Clin Nutr. 2014;100:539-47.

42. Deshmukh-Taskar PR, Nicklas TA, O'Neil CE, Keast DR, Radcliffe JD, Cho S. The relationship of breakfast skipping and type of breakfast consumption with nutrient intake and weight status in children and adolescents: the National Health and Nutrition Examination Survey 1999-2006. J Am Diet Assoc. 2010;110960:869-78

43. Schlundt DG, Hill JO, Sbrocco T, Pope-Cordle J, Sharp T. The role of breakfast in the treatment of obesity: a randomised clinical trial. Am J Clin Nutr. 1992:55(3):645-51.

44. Utter J, Scragg R, Mhurchu CN, Schaaf D. At-home breakfast consumption among New Zealand children: associations with body mass index and related nutrition behaviours. J Am Diet Assoc. 2007;107(4):570-6.

\section{Submit your next manuscript to BioMed Central and we will help you at every step:}

- We accept pre-submission inquiries

- Our selector tool helps you to find the most relevant journal

- We provide round the clock customer support

- Convenient online submission

- Thorough peer review

- Inclusion in PubMed and all major indexing services

- Maximum visibility for your research

Submit your manuscript at www.biomedcentral.com/submit
) Biomed Central 